\title{
QUADERNI Quaderni
}

Communication, technologies, pouvoir

101 | Été 2020

La fin des communicants politiques?

\section{Nazisme, modernisme et management}

David Forest

\section{OpenEdition}

\section{Journals}

Édition électronique

URL : https://journals.openedition.org/quaderni/1753

DOI : 10.4000/quaderni.1753

ISSN : 2105-2956

\section{Éditeur}

Les éditions de la Maison des sciences de l'Homme

\section{Édition imprimée}

Date de publication : 5 octobre 2020

Pagination : 139-143

\section{Référence électronique}

David Forest, « Nazisme, modernisme et management », Quaderni [En ligne], 101 | Été 2020, mis en ligne le 05 octobre 2020, consulté le 04 janvier 2023. URL : http://journals.openedition.org/quaderni/ 1753 ; DOI : https://doi.org/10.4000/quaderni.1753 


\section{Lecture croisée}

\section{Nazisme, modernisme et management}

par David Forest

Université Panthéon Sorbonne

Libres d'obéir. Le management, du nazisme à aujourd'hui.

Johann Chapoutot

Paris, Gallimard, coll. Nrf Essais, 2020

\section{Le modernisme réactionnaire. Haine de la raison et culte de la technologie aux sources du nazisme. Jeffrey Herf}

Montreuil, éd. L'Échappée, coll. Versus, 2018

1. Zygmunt Bauman, Modernité et holocauste, Paris, La Fabrique, 2002, p. 40.
Analysant l'holocauste comme un «test de modernité », Auschwitz comme une « extension du système industriel moderne », les criminels nazis comme des personnalités ordinaires saisies par la dynamique et le dispositif général de l'extermination, Zygmunt Bauman dans Modernité et holocauste, avait contribué, il y a voici vingt ans, à modifier significativement la perception du judéocide en le plaçant au cœur du processus de modernisation. " La civilisation moderne, selon Bauman, n'a pas été la condition suffisante de l'holocauste, mais elle en a été la condition nécessaire ». Elle en aurait fait une réussite organisationnelle et consacré le triomphe de la rationalisation bureaucratique au sens wébérien ${ }^{1}$.

Deux ouvrages sous la plume de spécialistes de l'histoire intellectuelle du nazisme, parus à quelques mois d'intervalle, explorent le " modernisme » nazi à rebours d'idées très largement répandues. La première veut que le nazisme a imposé un commandement dépourvu de liberté et d'autonomie, la seconde qu'il a été une "révolte politique et culturelle contre la modernité », farouchement hostile à la science et à la technique. Ils analysent la réception 
du nazisme respectivement parmi les juristes et ingénieurs, ainsi que leur apport spécifique à l'idéologie nazie.

Le court essai au style enlevé et au titre en forme d'oxymore, Libres d'obéir, de Johann Chapoutot, professeur à la Sorbonne, dessine les liens entre le style de commandement effectivement encouragé par le III ${ }^{e}$ Reich et les ressorts de l'idéologie managériale de brillants juristes allemands devenus membres de la SS, qui ont largement réinvesti leur corps de doctrine après-guerre. L'auteur prolonge ainsi les travaux de l'historien Dieter Rebentisch qui dès les années 1980 avait mis en évidence l'éloignement progressif du III Reich de l'administration (Verwaltung) statique au profit de la Menschenführung, qui présuppose que la communauté des membres (de la fonction publique, de l'entreprise...) a approuvé librement et s'est approprié l'ordre et la décision.

Publié en 1984 en Grande-Bretagne et désormais disponible en français, Le modernisme réactionnaire de Jeffrey Herf, professeur au College Park de l'université du Maryland, révèle l'attitude ambivalente du nazisme à l'égard de la modernité. Partant du constat que les aspects modernes du nazisme ont été négligés, cet essai de sociologie interprétative développe la thèse suivante : l'Allemagne accueillit au début du XX $\mathrm{X}^{\mathrm{e}}$ siècle, et après la prise du pouvoir par les nazis, un courant qualifié par l'auteur de «modernisme réactionnaire », qui visait à réconcilier les idées antimodernistes, romantiques et irrationalistes présentes dans le nationalisme allemand avec la technologie moderne.

Zygmunt Bauman avait dénoncé le mythe d'une science qui aurait été, avant tout, victime de persécutions sous le nazisme alors que la communauté scientifique allemande et son culte du rationalisme fut une des chevilles ouvrières de la machine nazie dont elle partagea largement l'idéologie. Il s'appuyait notamment sur l'implication des scientifiques biomédicaux dans l'élaboration, la mise en œuvre et la « gestion » des programmes raciaux ${ }^{2}$. Toutefois, selon Herf, le paradoxe essentiel du modernisme réactionnaire est qu'il rejeta la raison tout en vouant un culte à la technologie dont il offrit une vision esthétique.

Il entreprend sa généalogie et dessine une constellation intellectuelle qui associe des auteurs comme Werner Sombart, Oswald Spengler, Ernst Jünger, Hans Freyer, Carl Schmitt, Martin Heidegger et d'autres moins connus. Sa lecture invite à prendre en considération les différentes manières dont ils 
adhérèrent à la technologie moderne. Ainsi, Der Arbeiter (Le Travailleur), l'ouvrage de Jünger consacré aux rapports entre technologie et société, présente la technologie comme « la mobilisation du monde à travers la figure du travailleur».

Chapoutot revient également sur cet ouvrage important qui apparait comme un momentum. Au sein d'une modernité de «feu et d'acier », Jünger décrit et salue l'avènement d'un nouveau type humain : la figure du travailleur qui se substitue à l'individu comme valeur, principe et fin de l'organisation sociale. L'homme germanique est celui de la communauté et du travail. Partant, le bien-être, l'ergonomie, la convivialité, l'organisation de loisirs collectifs et la sécurité au travail seront considérées comme des facteurs de performance, et le signe selon Chapoutot, d'une "étonnante modernité nazie ».

Les ingénieurs allemands accueillent le nazisme avec, pour la plupart, un certain enthousiasme. À partir de l'expérience fondatrice de la guerre industrielle et des tranchées, le futur ministre de l'armement du Reich, Fritz Todt, élabore un discours articulant avec ferveur l'idéologie nazie à la politique culturelle des ingénieurs. Le « romantisme d'acier » de Goebbels veut unir la beauté de forêts germaniques à la puissance des usines, tout en persuadant l'opinion que la technologie est une manifestation extérieure de la volonté de puissance. Hitler rejette l'hostilité pour la technologie présente dans l'idéologie völkisch: l'esprit technique et le mythe racial nazi, en effet, devaient faire front commun contre le «matérialisme juif». Les juifs étaient, notamment, tenus pour responsables des mésusages de la technologie.

De leur côté, relève Chapoutot, les juristes allemands chargés de penser l'administration du grand Reich, recrutés par les nazis durant la crise ou ayant rallié le régime tels Wilhelm Stuckart et Werner Best, manifestent une " obsession de la vie », de la circulation, des flux alimentant les «forces vives » de la race, un culte de la "liberté germanique », et en contrepoint, une méfiance grandissante à l'égard de l'État, cet artefact figé, au temps long et à l'organisation réglée, reposant sur un culte de la Loi, de la norme abstraite et écrite qu'ils attribuent à l'influence juive. L'État contrarie l'élan vital et le mouvement car il fait prévaloir «l'encre de la loi sur le sang de la race et l'artifice sur la nature », thème présent dans Mein Kampf, qui postule que «l'État est un moyen en vue d'une fin », laquelle n'est autre que biologique et raciale. 
Si la phraséologie politique fondée sur les notions de mouvement et de dynamisme contribua à maintenir la force émotionnelle de l'idéologie nazie, le «romantisme d'acier» qui conservait un ethos antiscientifique et antirationnel, entrava selon Herf les innovations techniques à rebours des efforts menés en Russie, en Grande-Bretagne et aux États-Unis.

L'organisation administrative en agences (Anstalten) en charge d'une politique publique qui se multiplient à partir de 1933, est une invention de Reinhard Höhn. Entré au NSDAP en mai 1933 et dans la SS en 1934, premier adjoint de Reinhard Heydrich et un temps proche de Carl Schmitt, Höhn était chef du premier bureau de l'Amt II, un des onze départements de l'Hauptamt Volksdeutsche Mittelstelle, agence créée pour défendre les intérêts des Volksdeutsche descendants d'Allemands, nés et vivant hors des frontières du Reich. L'organisation Todt, créée en 1938 par Fritz Todt pour conduire nombre de travaux, des baraques des stalags au Mur de l'Atlantique, est une autre de ces agences. Leur création correspondait à la volonté de réformer l'organisation de l'État qui pour Hörn, n'est plus «l'entité politique suprême » apparu à l'époque moderne mais un « appareil » parmi d'autres résolument distingué du Führung, l'instance de commandement.

La « polycratie en temps réel » encouragée par les nazis reposait sur un «darwinisme administratif» issu des réflexions d'Herbert Spencer sur le darwinisme social: si le monde est le lieu de la guerre entre les races pour leur survie, il doit en être de même entre les services, les directions centrales et les agences. À partir de 1941, la « logique de radicalisation cumulative » consistant à laisser des initiatives locales concurrentes mettre en œuvre la Shoah, suscite l'approbation d'Hitler, d'Himmler et de Goebbels notamment, car elles « travaillent en direction du Führer ». Après la capitulation de l'Allemagne, ce n'est plus la communauté du sang mais l'entreprise et sa communauté de collaborateurs, qui seraient devenues le lieu de la «liberté », de la création et de l'épanouissement. Dans la doctrine managériale promue après-guerre par Hörn au sein de son académie de management, à Bad Harzburg, qui accueille la fine fleur des managers de l'industrie allemande voire internationale, il s'agit de donner des objectifs aux membres de l'entreprise pensée comme une communauté, de leur laisser une capacité de réflexion, de leur permettre de s'impliquer et décider par eux-mêmes des moyens à mettre en œuvre pour satisfaire leurs objectifs. Au cœur de cette doctrine, la « liberté d'obéir » n'est pas une injonction contradictoire car la seule liberté 
3. Voir notamment Florent Georgesco, « Libres d'obéir de Johann Chapoutot : le nazisme est-il soluble dans le management d'entreprise ? ", in Le Monde, 16 janvier 2020. réside dans le choix des moyens non des fins.

Certains ont reproché à Chapoutot, qui érige Hörn en prophète de la Nouvelle gestion publique (New public management), une réduction du management au nazisme présenté volens nolens comme matriciel ${ }^{3}$. Plutôt qu'un solide cordon ombilical théorique, c'est un réseau de correspondances ou réseau de signifiants qui est mis en lumière. Le genre de l'essai emportait, certainement, le risque d'une optique simplificatrice en dépit des préventions de l'auteur qui, en préambule, se garde de prêter au management une nature criminelle par essence. Le lecteur sortira convaincu en tout cas qu'il s'agit d'une technologie de pouvoir.

Dans sa postface à l'ouvrage de Herf intitulée : «le culte de la technologie », l'historien des sciences François Jarrige se demande si, toute proportion gardée, nous ne serions pas aussi victimes d'un culte irrationnel de la technologie confinant parfois à un fanatisme aveugle. Car le transhumanisme des prophètes de la Silicon Valley et les projets fondés sur le contrôle de tous les aspects de l'existence rappellent, s'il en était besoin, que les technologies, loin d'être neutres, façonnent le monde, appuyées sur des imaginaires qui leur donnent sens. 
